\title{
Comparative Analysis of Different CSP Plant Configurations in Saudi Arabia
}

\author{
H.Sumayli, A. Al Zahrani, A. Bindayel \\ King Abdullah City for Atomic and Renewable Energy, Riyadh, Kingdom of Saudi Arabia \\ A. Perdichizzi, G. Franchini, S. Ravelli \\ Department of Engineering and Applied Sciences, University of Bergamo, Italy
}

\begin{abstract}
The present paper compares the performance of different Concentrated Solar Power (CSP) plants. The first plant configuration is a regenerative Steam Rankine Cycle (SRC) rated 50 MW, with 8-hour full-load Thermal Energy Storage (TES) system. The alternative solution is an Integrated Solar Combined Cycle (ISCC), where the steam generated by the solar section is joined to the one produced in the Heat Recovery Steam Generator (HRSG) and is expanded in the steam turbine, producing $20 \mathrm{MW}$ of extra power. As far as the solar field is concerned, for each plant configuration two different technologies are considered: Parabolic Trough Collectors (PTC) and Central Receiver System (CRS), using respectively thermal oil and molten salt mixture as heat transfer fluid (HTF).

Commercial software and in-house computer codes are combined together to predict the CSP plant performance both on design and off-design conditions. Plants are supposed to be located in the Riyadh region (KSA). Results of yearly simulations on hourly basis are presented and discussed. Main outputs such as gross electricity production and cycle efficiency are reported. The goal of the paper is to evaluate the power production and the efficiency for the considered CSP technologies in real operating conditions.
\end{abstract}

Index Terms Concentrated Solar Power; Integrated Solar Combined Cycle; Solar Thermal Electricity.

\section{NOMENCLATURE}

$C C$

CRS

CSP

DNI

$G T$

HP

HRSG

HTF

ISCC

LP

PTC

$\mathrm{SH}$

SRC

ST

TES

combined cycle
central receiver system
concentrated solar power
direct normal irradiance
gas turbine
high pressure
heat recovery steam generator
heat transfer fluid
integrated solar combined cycle
low pressure
parabolic trough collector
superheater
steam Rankine cycle
steam turbine
thermal energy storage

combined cycle

central receiver system

concentrated solar power

direct normal irradiance

gas turbine

high pressure

heat transfer fluid

integrated solar combined cycle

low pressure

superheater

steam turbine

thermal energy storage

\section{INTRODUCTION}

$\mathrm{C}$ oncentrated Solar Power (CSP) plants are an attractive option in climate change mitigation scenarios, where power production by means of solar radiation can play a key role for $\mathrm{CO}_{2}$ emission reduction [1]. As far as solar field is concerned, four CSP technologies are available on the market: parabolic troughs, linear Fresnel reflectors, central receiver systems and parabolic dishes. Among these solutions, parabolic troughs and solar towers (with heliostat field and central receiver on the tower top) are installed in commercial plants. Moreover, in CSP plants heat can be stored: by using Thermal Energy Storage (TES) systems, CSP stations operation can be extended for many hours in a day, allowing overnight power production [2]. Furthermore, CSP plant technology is very scalable and it can be employed to generate power in sunny sites from a few megawatts up to hundreds.

Saudi Arabia is expected to experience robust growth in its solar power market, with a special focus on Concentrated Solar Power technology [3]. With a plan for adding $54 \mathrm{GW}$ of power generation capacity from renewable sources, $41 \mathrm{GW}$ of solar power will contribute to the mix of renewables in the Kingdom of Saudi Arabia by 2032: solar energy will be generated in the Kingdom by employing both photovoltaic (PV) technology and concentrated solar power (CSP) technology [4].

Most CSP power plants operate according to the Rankine cycle. Recently, Integrated Solar Combined Cycle (ISCC) power plants, composed of concentrating solar field and fuelfired Combined Cycle power units, have been introduced in the power generation sector as a technology with the potential to simultaneously reduce fossil fuel usage and the costs of solar power.

In spite of a large number of paper investigating plant performance of a single CSP technology, only a few works present a comparison between solar fields based on PTCs and solar tower. Solar collector efficiency is strongly related to site latitude and meteorological conditions (DNI, ambient temperature) [5]. Typically, PTCs can intercept a larger amount of incident radiation than heliostats in summer months, but their efficiency tends to dramatically decay in winter [6]. Comparing the results for parabolic troughs and tower plants, the latter typically provide a higher uniformity in the electricity production, due to a more constant collection capability of the 
resource all over the year. However, because of the larger spacing needed by the heliostats, the energy density is lower than for the PTC plants [7].

In the present paper, simulations of two CSP plant options, such as the SRC and the ISCC, were implemented for two different concentrating solar devices, i.e. parabolic trough and central receiver system. As a result, four cases were included in the comparison. Hourly and annual performance of the investigated solar power plants was evaluated for climate conditions related to Riyadh (KSA). Weather data were provided by Renewable Resource Atlas of Saudi Arabia.

\section{DESCRIPTION OF PLANT LAYOUTS}

\section{A. Steam Rankine Cycle}

The SRC configuration draws inspiration from a new CSP project to be held in Riyadh New City. The power block (Fig. 1 ) is a single reheat, regenerative Rankine cycle with 6 heaters: the feed water is preheated in three LP feed water heaters, a deaerator and two HP feed water heaters. An air-cooled condenser with a design condensing pressure of 0.06 bar at ISO condition was considered. The nominal steam temperature at turbine inlet depends on the heat transfer fluid (HTF) evolving in the solar field. In the PTC case, the HTF is assumed to be thermal oil (design temperature at solar field outlet/inlet of $392^{\circ} \mathrm{C} / 292^{\circ} \mathrm{C}$ ) whereas molten salt (design temperature at solar field outlet $/$ inlet of $550^{\circ} \mathrm{C} / 300^{\circ} \mathrm{C}$ ) is chosen for the CRS case. The thermal storage is conceived for a capacity of 8 hours: the PTC solar field is coupled with a 2-tank molten salt indirect storage whereas the CRS with a 2-tank direct storage. The aperture area of the two solar fields has been computed in order to keep below $5 \%$ the annual energy loss due to mirror defocusing. Primary design parameters are summarized in Table 1. No auxiliary boilers are included in the plant configurations.

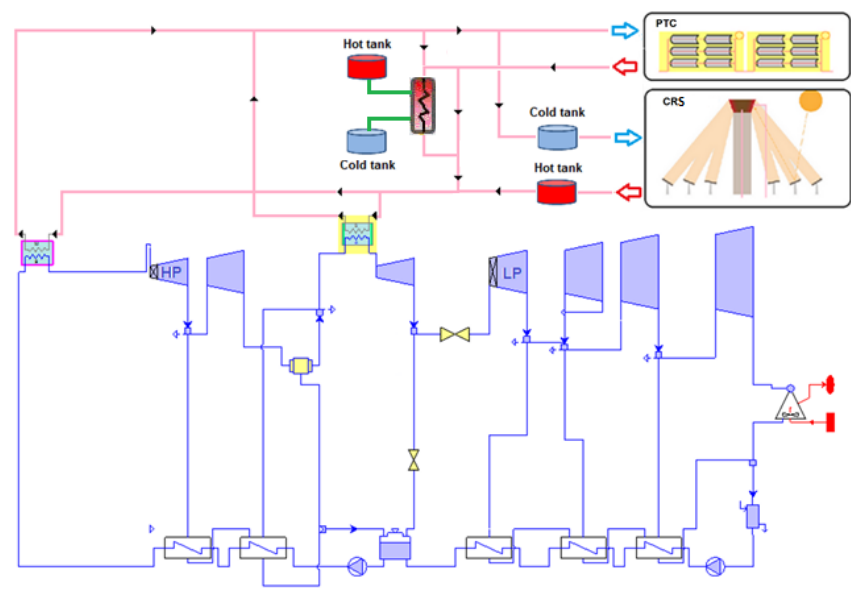

Fig. 1. Schematic of the SRC plant configuration.
TABLE I

DESIGN PARAMETERS OF SRC PLANT (ISO CONDITION)

\begin{tabular}{l|c|c}
\hline Design Parameter & PTC & CRS \\
\hline Gross power output $\left(\mathrm{MW}_{\mathrm{e}}\right)$ & \multicolumn{2}{|c}{50.0} \\
\hline Steam flow rate $(\mathrm{kg} / \mathrm{s})$ & 57.2 & 41.3 \\
\hline Turbine inlet temperature $\left({ }^{\circ} \mathrm{C}\right)$ & 360 & 540 \\
\hline Turbine inlet pressure $(\mathrm{bar})$ & 90 & 100 \\
\hline Condenser pressure $(\mathrm{bar})$ & \multicolumn{2}{|c}{0.06} \\
\hline Reheat temperature $\left({ }^{\circ} \mathrm{C}\right)$ & 310 & 485 \\
\hline Gross efficiency $(\%)$ & 38.2 & 42.9 \\
\hline Solar field aperture area $\left(\mathrm{m}^{2}\right)$ & 571200 & 558000 \\
\hline Tank volume $\left(\mathrm{m}^{3}\right)$ & 13474 & 4714 \\
\hline HTF mass flow rate $(\mathrm{kg} / \mathrm{s})$ & 542 & 311 \\
\hline
\end{tabular}

\section{B. Integrated Solar Combined Cycle}

An ISCC system combines a solar field and a gas fired CC power plant. The steam generated by the solar section is joined to the one produced in the HRSG and is expanded in the steam turbine. Steam turbine and condenser over sizing is needed to accommodate solar steam.

$\mathrm{CC}$ design parameters in fossil fuel operation are shown in the first part of Table II. The CC plant includes a Siemens SGT800 gas turbine rated $50.5 \mathrm{MW}_{\mathrm{e}}$ at ISO condition (Fig. 2). The steam section is based on a dual pressure HRSG generating steam at 69 bar and 7.7 bar. Steam is then expanded in a steam turbine producing $22.2 \mathrm{MW}_{\mathrm{e}}$. HP and LP evaporator were sized assuming pinch point temperature difference values of $9^{\circ} \mathrm{C}$ and $8^{\circ} \mathrm{C}$, respectively. Turbine efficiency values of $83 \%$ and $87.5 \%$ were set for HP and LP steam turbine sections. An air-cooled condenser with a design pressure of 0.06 bar at ISO conditions was considered. In the ISCC plant (see second part of Table II), a solar field was included for both PTC and CRS technologies. In the former, thermal oil was assumed at constant temperature values of $292^{\circ} \mathrm{C}$ and $392^{\circ} \mathrm{C}$ at the solar field inlet and outlet. In the latter, constant molten salt temperature values of $300^{\circ} \mathrm{C}$ and $550^{\circ} \mathrm{C}$ were set at the solar field inlet and outlet.

TABLE II

Design PARAMETERS OF CC POWER Plant (ISO CONDITION)

\begin{tabular}{l|c|c}
\hline Fossil fuel operation & \multicolumn{2}{|c}{50.5} \\
\hline GT power output $\left(\mathrm{MW}_{\mathrm{e}}\right)$ & \multicolumn{2}{|c}{$69-7.7$} \\
\hline HP-LP pressure $(\mathrm{bar})$ & \multicolumn{2}{|c}{$522-218$} \\
\hline HP - LP SH temperature $\left({ }^{\circ} \mathrm{C}\right)$ & \multicolumn{2}{|c}{$17.8-20.9$} \\
\hline HP - LP steam flow $(\mathrm{kg} / \mathrm{s})$ & \multicolumn{2}{|c}{0.06} \\
\hline Condenser pressure $(\mathrm{bar})$ & \multicolumn{2}{|c}{22.2} \\
\hline ST power output $\left(\mathrm{MW}_{\mathrm{e}}\right)$ & \multicolumn{2}{|c}{71.6} \\
\hline CC gross power $\left(\mathrm{MW}_{\mathrm{e}}\right)$ & \multicolumn{2}{|c}{131.1} \\
\hline Fuel consumption $\left(\mathrm{MW}_{\mathrm{th}}\right)$ & \multicolumn{2}{|c}{54.6} \\
\hline CC gross efficiency $(\%)$ & PTC & CRS \\
\hline ISCC & 92.1 & 92.6 \\
\hline ISCC gross power $\left(\mathrm{MW}_{\mathrm{e}}\right)$ & 70.3 & 70.7 \\
\hline Gross efficiency $(\%)$ & 115200 & 128400 \\
\hline Solar field aperture area $\left(\mathrm{m}^{2}\right)$ & 220 & 150 \\
\hline HTF mass flow rate $(\mathrm{kg} / \mathrm{s})$ & \multicolumn{2}{|c}{} \\
\hline
\end{tabular}




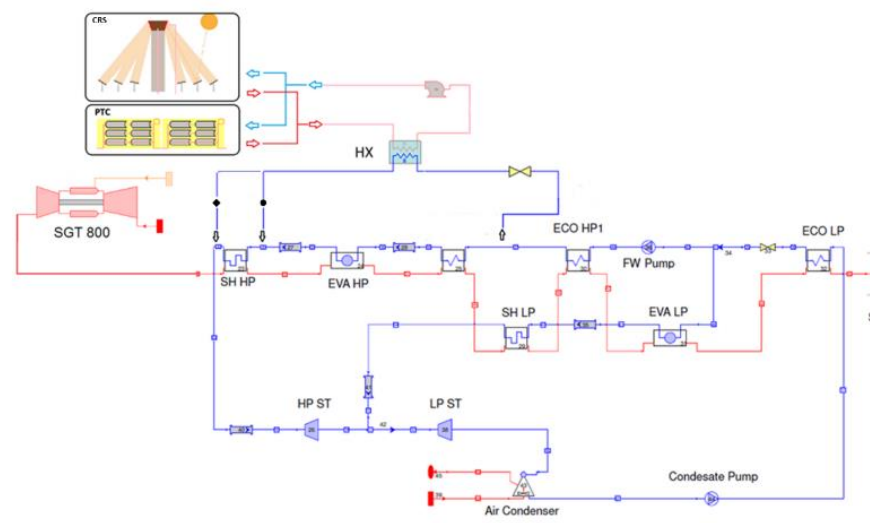

Fig. 2. Schematic of the ISCC plant configuration.

The thermal energy from the solar field is transferred to the bottoming cycle by means of a heat exchanger HX including an economizer, an evaporator and a superheater. HX receives preheated feedwater drawn from the HRSG, downstream of the first stage economizer (ECOHP1) and returns superheated steam. This mixes with the steam exiting the HP evaporator (see black circle in Fig. 2)/HP superheater (see black diamond) for PTC/CRS solution, respectively. The solar field size was set in order to achieve an extra power output (at ISO condition) of about 20 MWe keeping below 5\% the annual energy loss due to mirror defocusing. At design point, the ISCC supplies more than $92 \mathrm{MWe}$, with a gross efficiency of about $70 \%$ (referred to fuel input).

\section{SIMULATION METHOD AND ASSUMPTIONS}

The power block was modeled by Thermoflex ${ }^{\circledR}$ whereas Trnsys $^{\circledR}$ was used to model the solar fields, including the TES systems. The PTC overall efficiency under actual operating conditions was evaluated as follows:

$$
\eta_{P T C}=\eta_{\text {opt }} \cdot K-\left(A+C \cdot V_{\text {wind }}\right) \cdot \frac{\left(T_{a v}-T_{a m b}\right)}{I_{\text {beam }}}-\varepsilon \cdot B \cdot \frac{\left(T_{a v}^{4}-T_{\text {sky }}^{4}\right)}{I_{\text {beam }}}
$$

The $\eta_{P T C}$ formula (where $T_{a v}, T_{a m b}$ and $T_{s k y}$ are the HTF average temperature, the dry-bulb ambient temperature and the effective sky temperature for long wave radiation calculations, respectively, $V_{\text {wind }}$ is the wind speed, $\varepsilon$ is the absorber emissivity and $I_{\text {beam }}$ is the direct solar irradiance) was derived from [8]. The coefficients $A, B$ and $C$ were computed to fit the thermal efficiency curve of Schott PTR70 receivers under standard conditions [9]. The optical efficiency $\eta_{\text {opt }}(0.77)$ is related to the mirror reflectivity, glass transmissivity and receiver tube absorptivity. The incident angle modifier $K$ takes into account the effect of the non-perpendicularity of solar radiation and it is a function of the incidence angle.

Trnsys ${ }^{\circledR}$ was also used to model the heliostat solar field (120 $\mathrm{m}^{2}$ heliostat surface) and the tower receiver. The heliostat field performance was computed by means of an "efficiency matrix" derived from NREL data [10]. The solar tower was modeled in Trnsys ${ }^{\circledR}$ by using a typical performance map of a single Northfacing cavity receiver. The receiver was simulated as a simple black body absorber including radiative losses. An average mirror reflectivity of $90 \%$ was assumed.
The effect of dust accumulation on mirrors has been taken into account. A $0.2 \%$ reduction per day in mirror reflectivity and 1 wash per week have been considered both for troughs and heliostats.

Hour by hour, the Trnsys ${ }^{\circledR}$ model of the solar field provides exit HTF flow rate based on climate conditions. These values are transferred to Thermoflex ${ }^{\circledR}$ as an input for the HTF source. Thermoflex computes the power plant off-design performance for the current operating conditions.

\section{RESULTS AND DISCUSSION}

A compendium of the simulation results is here presented for SRC and ISCC configurations. First, the simulation outputs are shown by focusing on a typical hot/cold day in order to enlighten the plant behavior during off design conditions. Meteorological conditions in terms of ambient temperature and DNI profiles are reported in Fig. 3 for the selected days: one in winter and one in summer. The coldest ambient temperature is about $8^{\circ} \mathrm{C}$ in winter whereas the hottest conditions $\left(42^{\circ} \mathrm{C}\right)$ are achieved on summer afternoon. DNI gets the pick at $900 \mathrm{~W} / \mathrm{m}^{2}$ in summer. In winter the maximum solar radiation is about 870 $\mathrm{W} / \mathrm{m}^{2}$. Then global performance of the CSP plants has been assessed over a one-year period to find the most effective solution from an energy point of view.

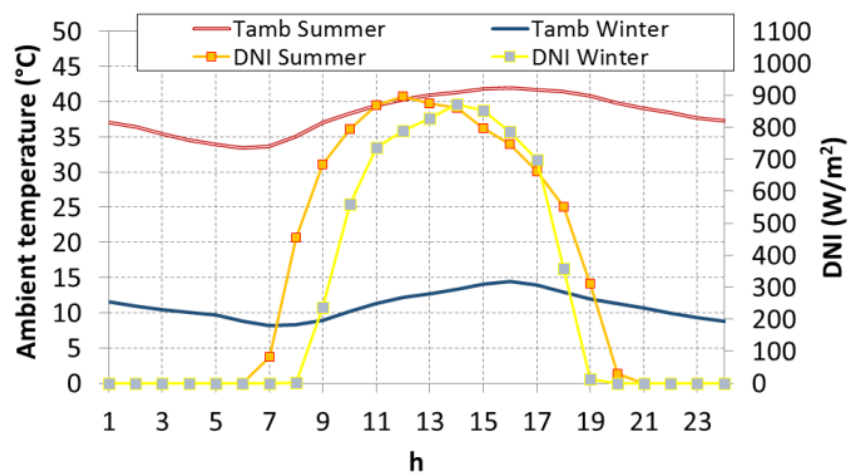

Fig. 3: Patterns of daily ambient temperature and solar irradiation for the selected winter/summer day.

\section{A. Steam Rankine Cycle}

Daily profiles of available solar radiation $(Q s o l)$ and collected power (Qcoll) are shown in Fig. 4 for the SRC coupled with PTC and CRS. In the summer day, PTC exhibit a very good capability to collect heat. Conversely, for the CRS, a reduction in the collected solar energy takes place in the central hours of the day, when the sun is approaching the zenith. This is related to geometric limitations of heliostats in reflecting the incident radiation toward the top of the tower. In winter, CRS maintains almost the same level of collected energy as in summer, whereas PTC efficiency dramatically decays, due to the cosine effect and, secondly, to low ambient temperatures. The hot tank level is also reported in Fig. 4. The collected solar energy is used primarily to transfer heat to the HTF fluid and, secondarily, to charge the hot storage. 

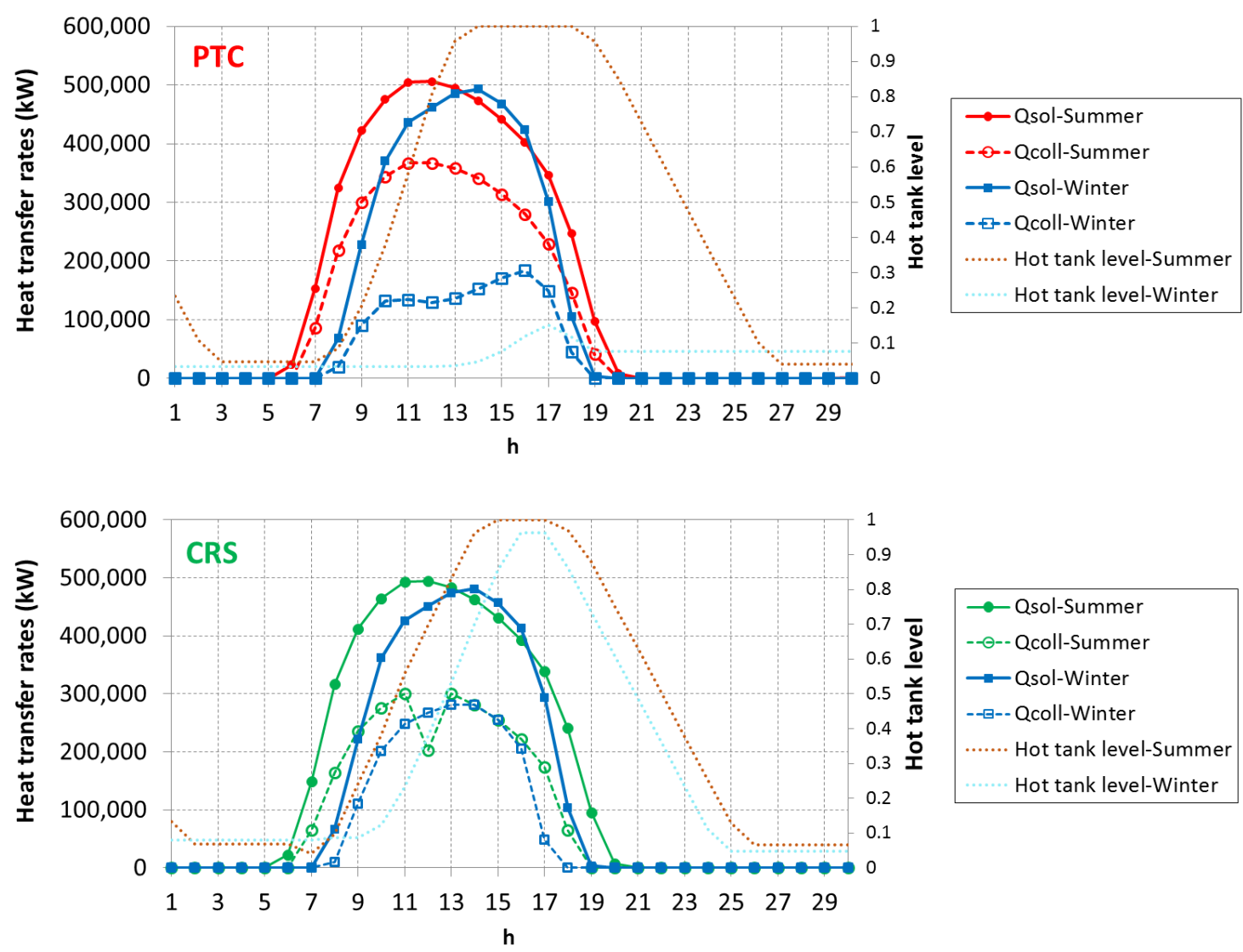

Fig. 4: Solar and collected heat transfer rates, together with hot tank level, for the SRC coupled with PTC (top) and CRS (bottom).

In case of CRS, the hot tank fills up (almost) completely during the day, whatever the climate. This means that the collected heat is far greater than the heat input required by the power plant, so that the hot tank is fully charged. For PTC, the hot tank is filled up only in summer. In cold weather, TES compensates the poor level of the collected solar energy by PTC: the rated power production is anyhow guaranteed at the expense of a very low hot tank level. The beneficial influence of TES on gross power production is evident from Fig. 5. In summer, TES is able to extend the operation hours of the SRC during evening and night times, whatever the solar field. Consequently, a gross power plateau around $43 \mathrm{MW}$ can be seen from $8^{\mathrm{h}}$ to $25^{\mathrm{h}}$. Note that this value is lower than design rate due to ambient temperature effects on Rankine cycle behavior. In winter, the rated power output can be ensured for a reduced number of hours in a day, especially for the PTC case (from $10^{\mathrm{h}}$ to $18^{\mathrm{h}}$ ).

Moving to the power block performance (Fig. 6), the PTC option under hot weather provides the lowest gross efficiency of about $33 \%$, due to the adverse combination of high ambient temperature (affecting the condenser pressure) and cycle efficiency penalty, with respect to the molten salt configuration.

On the opposite, the most effective CSP technology, when dealing with gross efficiency, is the CRS in winter, because of favorable ambient conditions and higher cycle efficiency. In the winter day, CRS is able to guarantee a gross electric efficiency of $43.5 \%$. It is evident from Fig.6 that CRS ensures an efficiency gain of about 5 percentage points, under the same climate conditions as PTC. The reader is remembered that gross efficiency is evaluated as the ratio of the gross power output to the solar heat input. Fig. 7 makes clear the influence of ambient temperature on the air-cooled condenser operation.
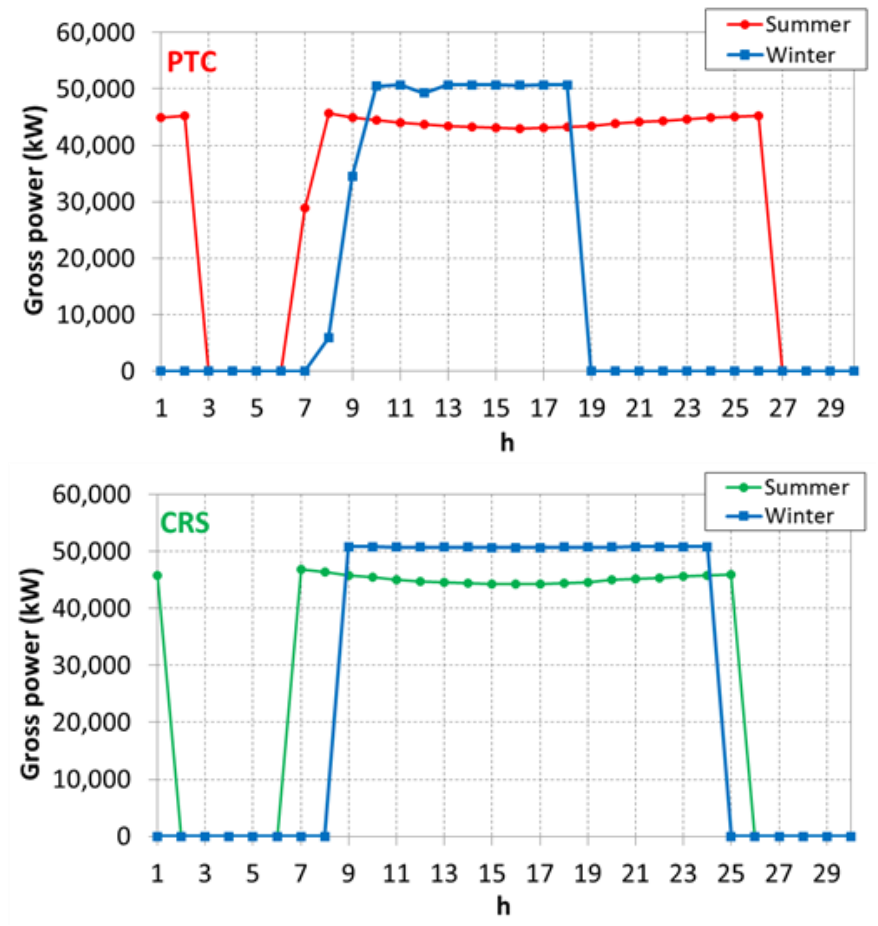

Fig. 5. Gross power production for the SRC coupled with PTC (top) and CRS (bottom). 


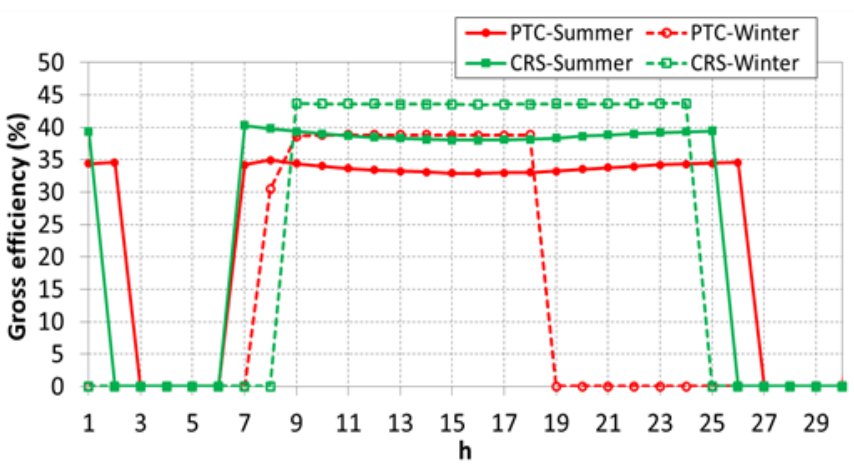

Fig. 6. Gross efficiency of the SRC.

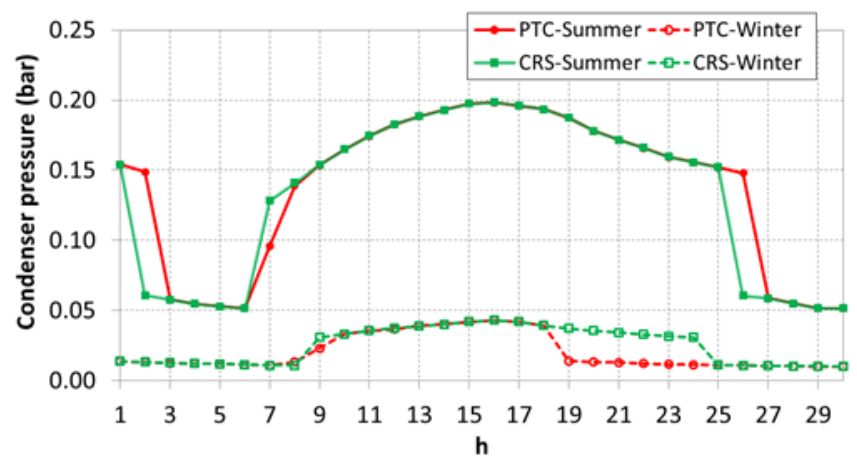

Fig. 7. Air-cooled condenser pressure in the SRC.

During the summer day, the condenser pressure reaches a maximum value of 0.2 bar at $16^{\mathrm{h}}$, as a consequence of ambient temperature as high as $42^{\circ} \mathrm{C}$. In the winter day condensing pressure is even lower than the design value of 0.06bar thanks to cold weather.

Monthly average solar and collected energy are presented in Fig. 8, together with gross generation. PTC can intercept a very high fraction of the solar energy in the summer months, due to lower cosine losses. Conversely, the solar energy intercepted by the CRS is much more constant during the year, thanks to higher optical efficiency in the winter months. This translates into an almost flat power production (Egross) for CRS across the whole year, for a total amount of $237.8 \mathrm{GWh}$. On the other hand, the power output from the PTC solar field gets the peak on July and August (24.6 MWh) but the annual amount of Egross (218.7 $\mathrm{GWh}$ ) is less than that of CRS.

\section{B. Integrated Solar Combined Cycle}

In the current section, PTC and CRS solar field options are included in an ISCC. Figure 9 demonstrates that the solar contribution in an ISCC allows increasing the gross power in daylight hours, with respect to the fossil-fueled CC. In summer, PTC and CRS provide roughly the same incremental solar power, apart from a single hour $\left(12^{\mathrm{h}}\right)$ when CRS is penalized. In winter, the CRS, being able to collect higher fraction of solar energy than PTC, provides the highest level of gross power. The peak of about $94 \mathrm{MW}$ is achieved on winter day, at $11^{\mathrm{h}}$, thanks to a favorable combination of high collected solar energy and cold weather.
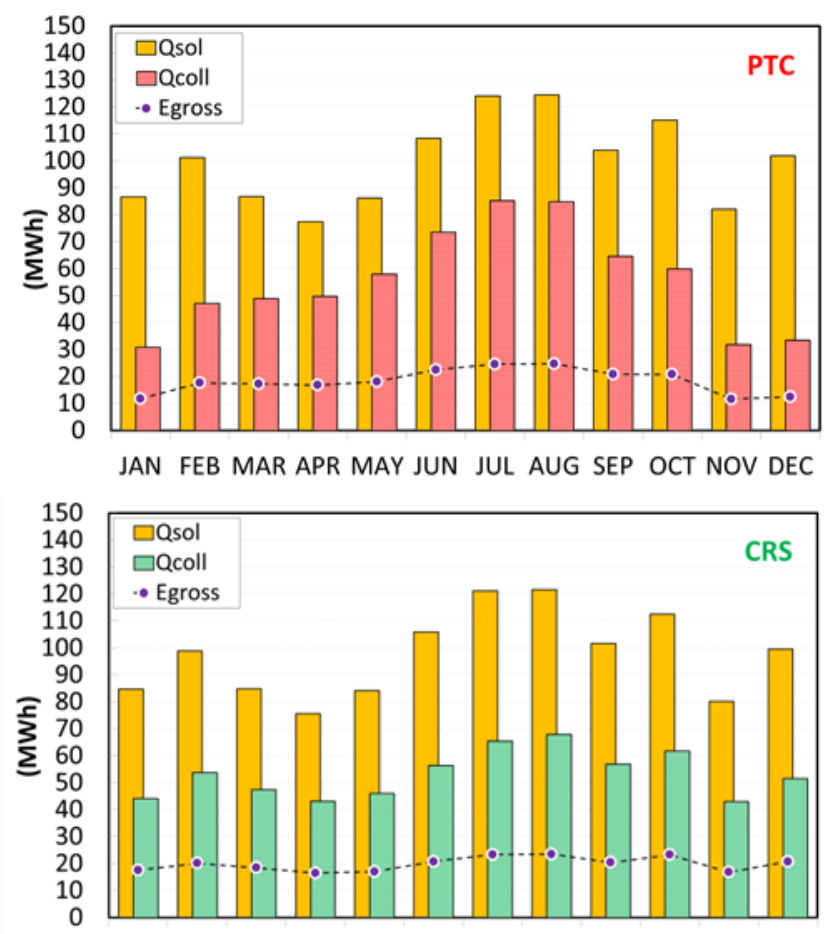

JAN FEB MAR APR MAY JUN JUL AUG SEP OCT NOV DEC

Fig. 8. Monthly results in terms of solar and collected energy, together with gross production.
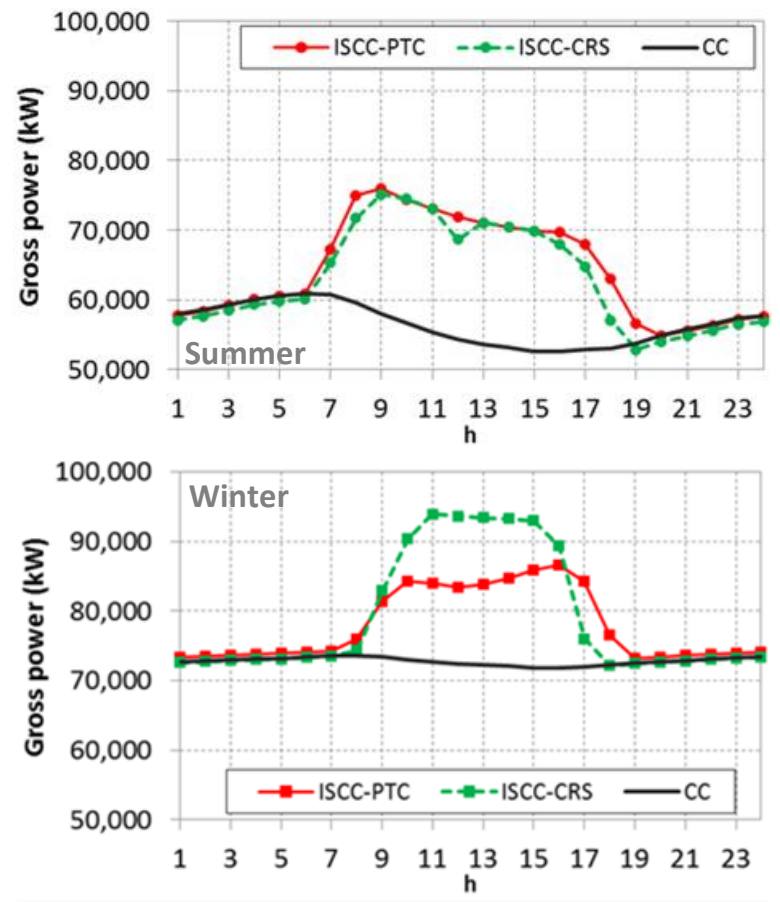

Fig. 9. ISCC gross power production in summer (top) and winter (bottom) day.

Profiles of gross efficiency, defined as the gross power output divided by the fossil fuel input, are depicted in Fig. 10. The extra power provided by the solar contribution makes the gross efficiency increase, as compared to the reference CC. The peak value of about $71 \%$ gross efficiency occurs from $11^{\mathrm{h}}$ to $15^{\mathrm{h}}$ in winter day for the CRS option, thanks to high solar-tothermal efficiency ensured by the solar tower, combined with 
low ambient temperature. In summer, the solar power provided by the PTC technology makes the gross efficiency increase to about $68 \%$ in the central hours of the day, whereas, in the same time of the winter day, the gross efficiency is lower than $65 \%$.
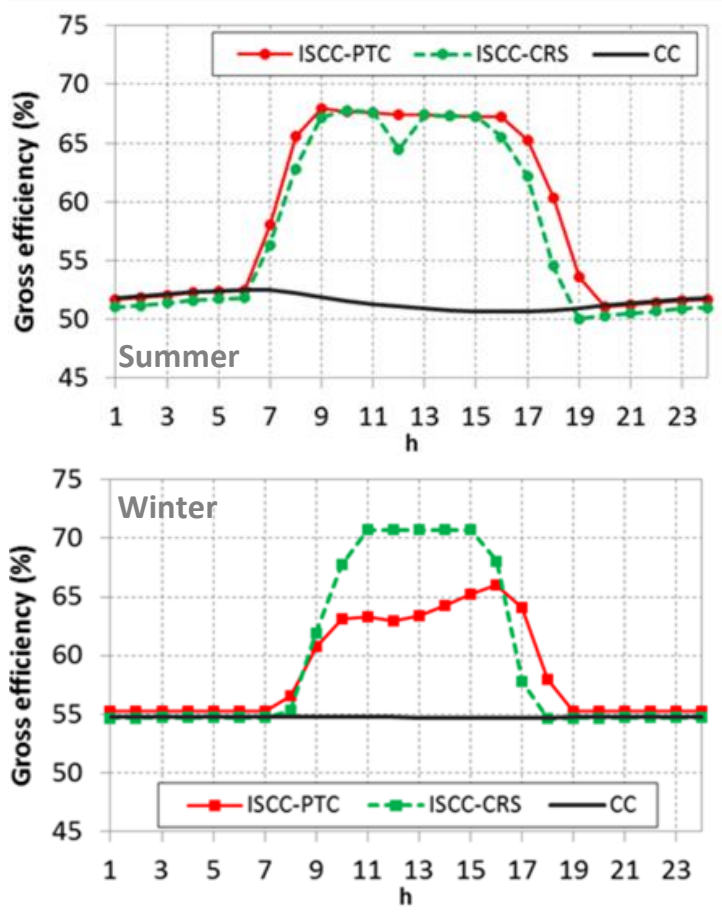

Fig. 10. ISCC gross efficiency in summer (top) and winter (bottom) day.

Obviously, during night hours, ISCC and CC show roughly the same performance in terms of gross power output and efficiency, except for negligible discrepancy due to the admission of the solar steam flow rate into the heat recovery steam generator. Since the investigated SRC is fully renewable, whereas solar contribution in the ISCC allows an increase in the power produced by a reference fossil fueled $\mathrm{CC}$, the degree of plant hybridization was evaluated by using the solar fraction $S F$ :

$S F=\frac{Q_{t h, s o l}}{Q_{\text {th,sol }}+Q_{\text {th,fuel }}} * 100$

The amount of thermal energy provided by the solar technology $\left(Q_{t h, s o l}\right)$ is divided by the total thermal input (the sum of solar and fuel thermal input $\left.Q_{t h, f u e l}\right)$. Fig. 11 reports the hourly $S F$ profiles for the investigated hybrid combined cycles. During daylight hours, the $S F$ belongs to the range between $30 \%$ and $35 \%$ for both the concentrating solar systems in summer day, with CRS providing slightly higher $S F$ than PTC. In winter the $S F$ for the ISCC with PTC falls down below $22 \%$, due to the above mentioned limitations of this solar technology in cold weather, whereas CRS can guarantee a much higher $S F$ up to $30 \%$.

Figure 12 highlights the ISCC incremental energy production month by month, with respect to the reference CC. As expected, the CRS option works better than PTC in winter months. Both PTC and CRS suffer for a reduction in the energy output in summer months, since gas turbine underperforms in hot weather.

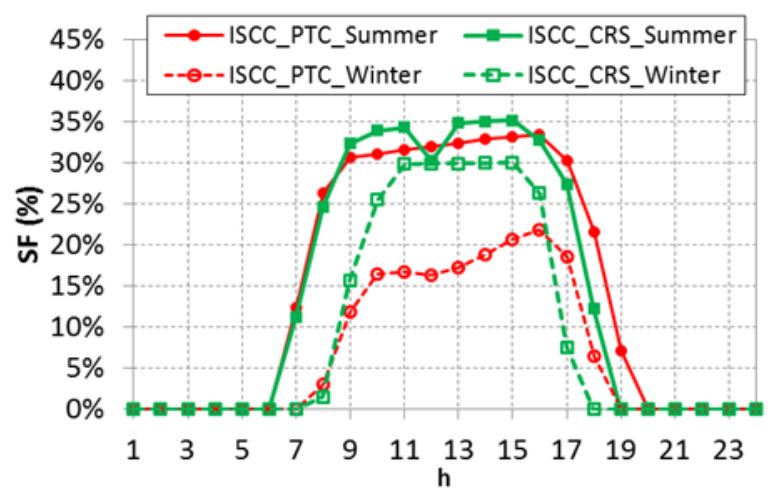

Fig. 11. ISCC solar fraction.

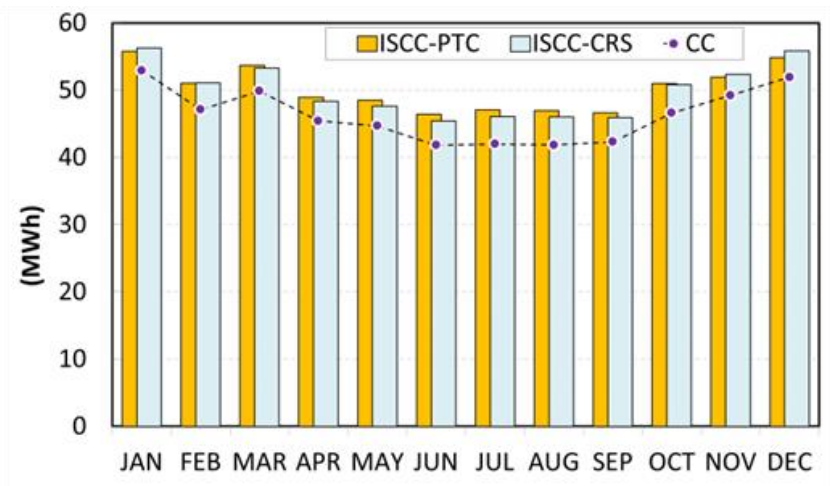

Fig. 12: ISCC vs. CC monthly gross production.

\section{Annual performance}

In order to globally assess the performance of the two investigated configurations, the annual energy balance reported in Table III has been evaluated. Before any performance analysis is carried out, it should be specified that the variable defined as "Solar Egross" corresponds to: i) the gross generation for the SRC over a one-year period; ii) the extra power for the ISCC, with respect to the CC:

Solar $E_{\text {gross }}=\sum_{h=1}^{8760}\left(\operatorname{Pgross}_{I S C C}-\eta_{C C} Q_{\text {th }, \text { fuel }}\right)$

where $\eta_{C C}$ is the efficiency of the reference CC operating at the same hour-by-hour ambient temperature conditions, with $Q_{\text {th,fuel }}$ as fuel energy input.

The solar energy conversion efficiency of SRC and ISCC was computed by the following:

$\eta_{\text {solar } / \text { thermal }}=\frac{Q \text { coll }}{Q \text { sol }} * 100$
$\eta_{\text {solar / electric }}=\frac{\text { Solar } E_{\text {gross }}}{Q \text { sol }} * 100$

Focusing on the SRC annual performance, the PTC option shows higher solar-to-thermal efficiency than the CRS case $(55.7 \%$ vs. $54.4 \%)$. But, looking at the solar-to-electric efficiency, it is clear that CRS is the most effective technology for converting solar energy into electric power (20.3\% vs. 
18.3\%). As far as the ISCC is concerned, the ISCC coupled with PTC is the best solution, both in terms of solar-to-thermal efficiency (55.4\%) and solar-to-electric efficiency (19.5\%).

TABLE III

ANNUAL PERFORMANCE OF THE INVESTIGATED CSP LAYOUTS

\begin{tabular}{l|c|c|c|c}
\hline \multirow{2}{*}{ Performance } & \multicolumn{2}{|c|}{ SRC } & \multicolumn{2}{c}{ ISCC } \\
\cline { 2 - 5 } & PTC & CRS & PTC & CRS \\
\hline Qsol $(\mathrm{GWh})$ & 1198 & 1170 & 242 & 269 \\
\hline Qcoll $(\mathrm{GWh})$ & 668 & 637 & 134 & 146 \\
\hline Solar Egross $(\mathrm{GWh})$ & 219 & 238 & 47.1 & 46.0 \\
\hline$\eta_{\text {solar/thermal }}(\%)$ & 55.7 & 54.4 & 55.4 & 54.1 \\
\hline$\eta_{\text {solar/lectric }}(\%)$ & 18.3 & 20.3 & 19.5 & 17.1 \\
\hline $\mathrm{SF}(\%)$ & 100 & 100 & 10.7 & 11.7 \\
\hline
\end{tabular}

\section{CONCLUSIONS}

A simulation procedure accounting for off design performance of both the solar field and the power block has been used to model the annual operation of two CSP plants: one is a SRC power plant, the other is an ISCC. Each of the two layout options has been coupled with two different CSP technologies, PTC and CRS. Accordingly, four cases were compared in terms of electricity generation from solar energy and solar-to-electric conversion efficiency. The Riyadh region was chosen as the location of the CSP plants.

From an energetic point of view, the following conclusions can be drawn over a one year period:

i) PTC can provide slightly higher solar-to-thermal efficiency than CRS, whatever the power block.

ii) PTC can be evaluated as the best technology for ISCC application, thus ensuring the highest solar-to-electric efficiency.

iii) Conversely, in a SRC, the most effective solution for converting solar energy into electric power is provided by CRS, allowing for a solar-to-electric efficiency gain of about 2 percentage points over PTC.

\section{REFERENCES}

[1] E. Massetti, E.C. Ricci, "An assessment of the optimal timing and size of investments in concentrated solar power", Energy Economics, vol. 38, pp.186-203, 2013.

[2] T.R. Mancini, "Spain pioneers grid-connected solar-tower thermal power", SolarPaces, 2011.

[3] A. Abdelhamid, "Focusing on CSP, Saudi Arabia to Add 41GW Solar Power by 2032", May $18^{\text {th }} 2015$, http://planetsave.com/2015/05/18/focusing-on-csp-saudiarabia-to-add-41gw-solar-power-by-2032/.

[4] TechSciResearch, "Saudi Arabia Solar Power Market Forecast and Opportunities (2020)", April 2015.

[5] H.L. Zhang, J. Baeyens, J. Degrève, G. Caceres, "Concentrated solar power plants: Review and design methodology", Renewable and Sustainable Energy Reviews, vol. 22, pp. 466-481, 2013.

[6] G. Franchini, A. Perdichizzi, S. Ravelli, G. Barigozzi, “A comparative study between parabolic trough and solar tower technologies in Solar Rankine Cycle and Integrated Solar Combined Cycle plants", Solar Energy, vol. 98, pp. 302-314, 2013.

[7] S. Izquierdo, C. Montañes, C. Dopazo, N. Fueyo, "Analysis of CSP plants for the definition of energy policies: the influence on electricity cost of solar multiples, capacity factors and energy storage", Energy Policy, vol. 38, pp. 6215-6221, 2010.

[8] S.D. Odeh, G.L. Morrison and M. Behnia, "Modelling Of Parabolic Trough Direct Steam Generation Solar Collectors", Solar Energy, Vol. 62, No. 6, pp. 395-406, 1998.

[9] T. Moss, D. Brosseau, "Testing capabilities NSTTF (AZTRAK) rotating platform. Sandia National laboratories”, New Mexico, 2007.

[10] N. Blair, A. Dobos, J. Freeman, T. Neises, M. Wagner, T. Ferguson, P. Gilman, S. Janzou, "System Advisor Model, SAM 2014.1.14 - General Description", Nat. Renew. Energy Lab, Denver, CO, USA, Tech. Rep. NREL/TP6A20-61019, February 2014. 